\title{
ISOTERM ADSORPSI TOLUENA PADA ARANG AKTIF STROBILUS PINUS (Pinus merkusii)
}

\author{
Andre G. Kalensun ${ }^{1}$, Audy D. Wuntu ${ }^{1}$ dan Vanda S. Kamu ${ }^{1}$ \\ ${ }^{1}$ Program Studi Kimia FMIPA Universitas Sam Ratulangi \\ Jl. Kampus Unsrat Manado, 95115 \\ e-mail: andre_geovanny@ymail.com; wuntudenny@unsrat.ac.id; vandakamu@yahoo.com
}

\begin{abstract}
ABSTRAK
Adsorpsi senyawa organik volatil toluena pada arang aktif yang dibuat dari strobilus pinus telah diteliti. Dalam penelitian ini arang aktif strobilus pinus dikarbonisasi pada suhu $400{ }^{\circ} \mathrm{C}$ dan diaktivasi dengan larutan $\mathrm{ZnCl}_{2}$. Eksperimen adsorpsi selama 24 jam dalam wadah tertutup berukuran $6.5 \mathrm{~L}$ yang berisi gas toluena $0.4 ; 0.8 ; 1.2 ; 1.6$ dan $2 \mathrm{~mL}$. Data yang diperoleh diuji dengan model isoterm adsorpsi Dubinin-Raduskevich. Untuk kapasitas dan energi adsorpsi toluena dihitung dengan persamaan Dubinin-Raduskevich. Hasil eksperimen menunjukkan bahwa kapasitas adsorpsi $\left(\mathrm{W}_{0}\right)$ arang aktif strobilus pinus yang teraktivasi adalah $0,1027 \mathrm{~cm}^{3} / \mathrm{g}$ dan energi adsorpsi $\left(\mathrm{E}_{0}\right)$ adalah $13,286 \mathrm{~kJ} / \mathrm{mol}$. Sedangkan kapasitas adsorpsi $\left(\mathrm{W}_{0}\right)$ arang strobilus pinus tanpa pengaktivasi adalah $0,0267 \mathrm{~cm}^{3} / \mathrm{g}$ dan energi adsorpsi $\left(\mathrm{E}_{0}\right)$ adalah $5,941 \mathrm{~kJ} / \mathrm{mol}$.
\end{abstract}

Kata kunci: arang aktif, strobilus pinus (Pinus merkusii), adsorpsi

\section{ISOTHERM ADSORPTION OF TOLUENE ONTO ACTIVATED CARBON MADE FROM STROBILUS PINE (Pinus merkusii)}

\begin{abstract}
The adsorption isotherm of toluene, an organic volatile compound, onto activated carbon prepared from strobilus pine was investigated. In this research, the carbon was carbonized at $400{ }^{\circ} \mathrm{C}$ and activated by $\mathrm{ZnCl}_{2}$. The adsorption isotherm experiment was conducted for 24 hours in six $6.5 \mathrm{~L}$ closed chambers, each was filled with $0.4 ; 0.8 ; 1.2 ; 1.6$ and $2.0 \mathrm{~mL}$ of toluene. The data were fitted to Dubinin-Raduskevich adsorption isotherm model in order to measure the adsorption capacity and the adsorption energy. The results showed that the adsorption capacity and the adsorption energy for the activated strobilus pine were $0.1027 \mathrm{~cm}^{3} / \mathrm{g}$ and $13.286 \mathrm{~kJ} / \mathrm{mol}$ respectively, while for the unactivated strobilus pine were $0.0267 \mathrm{~cm}^{3} / \mathrm{g}$ and $5.941 \mathrm{~kJ} / \mathrm{mol}$ respectively.
\end{abstract}

Key word: activated carbon, strobilus pine (Pinus merkusii), adsorption.

\section{PENDAHULUAN}

Indonesia merupakan negara yang memiliki iklim tropis dan hampir seluruh wilayahnya mendapat sinar matahari yang terik dalam intensitas besar disetiap harinya. Negara berkembang ini juga memiliki mobilitas masyarakat harian yang sangat bervariasi apalagi bagi mereka yang bermukim didaerah perkotaan. Hal ini sering memicu kecenderungan peningkatan penggunaaan pendingin udara dalam ruangan. Pemakaian peralatan seperti ini mensyaratkan ruangan tertutup dengan laju pertukaran udara yang sekecil mungkin antara udara luar maupun dalam ruangan. Dengan laju pertukaran udara yang kecil dapat mempertahankan suhu ruangan sehingga tidak berubah-ubah (isoterm). Kondisi yang seperti ini dapat menurunkan kualitas udara dalam ruangan karena memungkinkan terjadinya peningkatan konsentrasi partikel, $\mathrm{CO}_{2}$, CO, bakteri, dan senyawa organik volatil.

Toluena merupakan senyawa aromatik (turunan benzena) yang digunakan 
sebagai bahan bakar pesawat terbang dan juga pelarut cat, dengan sifat karsinogenik dan mutagenik (Ham, 2005). Toluena dapat ditemukan dalam kehidupan manusia seperti pada produk parfum, pewarna, plastik, dan obat-obatan (Warsito, 2007).

Berbagai metode telah dikembangkan untuk meningkatkan kualitas udara dalam ruangan tertutup, diantaranya adalah filtrasi, pembentukan ion, dan presipitasi elektrostatik. Meskipun metode filtrasi cukup efektif untuk menyingkirkan partikel tersuspensi tetapi metode ini tidak mampu menghilangkan senyawa organik volatil dari udara (Anonim, 2006). Metode lain yang dapat digabungkan dengan metode filtrasi adalah metode adsorpsi melalui penggunaan adsorben yang mampu mengadsorpsi senyawa organik volatil seperti arang aktif.

Arang aktif adalah arang yang telah diaktivasi sehingga pori-porinya terbuka dan memiliki daya jerap yang tinggi. Arang aktif merupakan adsorben yang baik dan dapat digunakan untuk pemurnian, menghilangkan warna dan bau, deklorinasi, detoksifikasi, penyaringan, pemisahan, dan dapat dipergunakan sebagai katalis (Bansal et al., 1988).

Tanaman Pinus adalah tanaman yang tumbuh subur di berbagai jenis kondisi dan dapat menutupi lokasi-lokasi yang terjal, jurang ataupun gunung-gunung yang tinggi. Tanaman ini memiliki alat reproduksi jantan dan betina yang sering disebut dengan strobilus. Kebanyakan masyarakat awam mengenal strobilus dengan sebutan buah pinus, namun para ahli biologi tidak mengklasifikasikan strobilus sebagai buah karena tidak memenuhi syarat sebagai buah melainkan sifatnya yang lebih menyerupai bunga. Pemanfaatan strobilus pinus masih sangat terbatas dengan hanya dijadikan sebagai hiasan dan berakhir sebagai limbah.

Arang aktif dalam pemurnian air dan limbah memang telah lama diaplikasikan oleh banyak pihak, namun belum ada informasi tentang penelitian yang mengevaluasi penggunaan arang aktif strobilus pinus untuk mengurangi senyawa organik volatil dari lingkungan ruangan tertutup. Penelitian ini diharapkan akan memberi nilai tambah bagi pemanfaatan strobilus pinus yang masih kurang daya gunanya.

\section{METODOLOGI PENELITIAN}

\section{Waktu dan Tempat}

Penelitian dilakukan selama dua bulan, (Juni - Juli 2012), di Laboratorium Advance Fakultas Matematika dan Ilmu Pengetahuan Alam Universitas Sam Ratulangi Manado.

\section{Bahan dan Alat}

Bahan yang digunakan dalam penelitian ini adalah strobilus pinus yang diambil di KotaTomohon, Sulawesi Utara. Bahan-bahan kimia yang digunakan yaitu toluene pekat, larutan $\mathrm{ZnCl}_{2} 10 \%$, akuades, dan alumunium foil.

Alat yang digunakan yaitu: tanur, oven, desikator, cawan porselin, penjepit cawan, peralatan gelas, gelas wol, dan rangkaian alat adsopsi.

\section{Metode Penelitian}

Penelitian dilakukan dalam dua tahap, yaitu pertama pembuatan dan uji kualitas arang aktif strobilus pinus dan yang kedua adalah percobaan adsorpsi toluena pada arang aktif strobilus pinus dalam model ruangan tertutup.

\section{a. Pembuatan dan uji kualitas arang aktif strobilus pinus \\ - Pembuatan Arang Aktif Strobilus Pinus}

Strobilus pinus yang dimasukkan ke dalam cawan porselin dan dikarbonisasi dalam tanur pada suhu $400{ }^{\circ} \mathrm{C}$. Arang yang dihasilkan kemudian diaktivasi dengan larutan $\mathrm{ZnCl}_{2} \quad 10 \%$ selama 24 jam. Arang yang telah diaktivasi dimasukkan ke dalam cawan porselin dan dipanaskan kembali menggunakan tanur pada suhu $500{ }^{\circ} \mathrm{C}$ selama 2 jam. Setelah dipanaskan, arang aktif yang diperoleh kemudian dicuci dengan akuades hingga mencapai $\mathrm{pH}$ netral. Selanjutnya arang aktif yang diperoleh dalam oven selama 3 jam pada suhu $110{ }^{\circ} \mathrm{C}$. Kemudian arang aktif siap untuk proses analisis selanjutnya.

\section{Uji kualitas arang aktif - Uji Kadar Air}

Sebanyak dua gram sampel arang aktif ditempatkan dalam cawan porselin yang telah diketahui berat keringnya. Cawan porselin yang telah berisi sampel dipanaskan 
dalam oven pada suhu $105{ }^{\circ} \mathrm{C}$ selama tiga jam. Didinginkan dalam desikator selama satu jam, kemudian ditimbang.

Kadar air dihitung dengan persamaan:

$$
\text { Kadar air }(\%)=\left(\frac{a-b}{b}\right) \times 100 \%
$$

dengan:

$a=$ berat sampel sebelum pemanasan

$b=$ berat sampel sesudah pemanasan

\section{- Uji Kadar Abu}

Sebanyak dua gram sampel arang aktif ditempatkan dalam cawan porselin yang telah diketahui berat keringnya.Cawan porselin yang telah berisi sampel dipanaskan dalam tanur pada suhu $750{ }^{\circ} \mathrm{C}$ selama enam jam. Didinginkan dalam desikator selama satu jam kemudian ditimbang.

$$
\text { Kadar abu }(\%)=\frac{a}{b} \times 100 \%
$$

dengan $a=$ berat sisa sampel

$$
b=\text { berat awal sampel }
$$

\section{- Uji kadar zat mudah menguap}

Sebanyak dua gram sampel arang aktif dimasukkan ke dalam cawan porselin yang diketahui berat keringnya. Sampel dipanaskan dalam tanur pada suhu $950{ }^{\circ} \mathrm{C}$ selama 10 menit (cawan ditutup serapat mungkin). Didinginkan dalam desikator selama satu jam kemudian ditimbang.

Kadar zat mudah menguap $(\%)=\left(\frac{a-b}{b}\right) \mathrm{x}$ $100 \%$

dengan, $a=$ berat awal sampel

$b=$ berat setelah pemanasan

\section{- Penentuan Kadar karbon Terikat}

Karbon dalam arang adalah zat yang terdapat pada fraksi hasil pirolisis selain abu (zat organik) dan zat-zat atsiri yang masih terdapat pada pori-pori arang. Kadar karbon terikat dihitung dari nilai kadar zat mudah menguap dan kadar abu dengan menggunakan persamaan:

Kadar karbon terikat $(\%)=100 \%-(b+c)$

Dimana, $b=$ kadar zat mudah menguap (\%)

$$
c=\text { kadar abu }(\%)
$$

\section{c. Eksperimen Adsorpsi Toluena pada Arang Aktif Strobilus Pinus}

Sebanyak 10 gram arang aktif strobilus pinus ditempatkan ke dalam cawan porselin, kemudian dipanaskan dalam oven pada suhu $110{ }^{\circ} \mathrm{C}$ selama 3 jam. Selanjutnya sampel didinginkan dalam desikator selama satu jam. Arang aktif selanjutnya ditempatkan di atas gelas arloji yang telah diketahui beratnya dan terbuka pada kedua ujungnya.Kemudian dimasukkan ke dalam wadah plastik berukuran $6.5 \mathrm{~L}$ yang telah di desain. Setelah itu wadah plastik tersebut dimasukkan 0.4 $\mathrm{mL}$ toluena tanpa menyentuh arang aktif, dan segera mungkin wadah plastik ditutup dan kipas dihidupkan. Toluena akan menguap dalam wadah plastik dan uap toluena akan diadsorpsi oleh arang aktif hingga tercapai kesetimbangan. Proses ini akan berlangsung dalam 24 jam dan selanjutnya berat arang aktif ditimbang. Prosedur ini kemudian diulangi untuk volume toluena pada 0.8: 1.2: 1.6: dan $2 \mathrm{~mL}$

\section{HASIL DAN PEMBAHASAN}

\section{Pembuatan Arang Aktif Strobilus Pinus}

Bahan utama yang dijadikan arang aktif yaitu strobilus pinus. Untuk mendapatkan arang aktif yang diinginkan, terlebih dahulu harus melalui dua tahap pengolahan yaitu tahap karbonisasi dan tahap aktivasi. Arang aktif yang dihasilkan berbentuk granular dan kondisi fisiknya berwarna hitam pekat.

\section{Uji Kualitas Arang Aktif Strobilus Pinus}

Hasil uji kualitas arang aktif strobilus pinus dapat dilihat pada Tabel 1. Analisis arang aktif meliputi kadar air, kadar zat mudah menguap, kadar abu, dan kadar karbon terikat.

Tabel 1: Kualitas arang aktif strobilus pinus

\begin{tabular}{|c|c|c|}
\hline Uji Kualitas & $\begin{array}{c}\text { Hasil } \\
\text { Eksperimen }\end{array}$ & SNI \\
\hline Kadar Air & $2.046 \%$ & Maks. $4.4 \%$ \\
\hline Kadar Abu & $2.448 \%$ & Maks. 2.5\% \\
\hline $\begin{array}{c}\text { Zat Mudah } \\
\text { Menguap }\end{array}$ & $6.089 \%$ & Maks. 15\% \\
\hline $\begin{array}{c}\text { Kadar Karbon } \\
\text { Terikat }\end{array}$ & $91.462 \%$ & Min. $80 \%$ \\
\hline
\end{tabular}

\section{Kadar Air}

Kadar air menunjukkan jumlah air yang teradsorpsi pada arang aktif. Air dapat teradsorpsi pada karbon melalui pembentukan ikatan hidrogen dengan gugus gugus karboksil (-COOH) dan hidroksil ($\mathrm{OH})$ di permukaan karbon. Kadar air yang terukur pada eksperimen ini adalah $2.046 \%$. 
Nilai kadar air arang aktif strobilus pinus lebih kecil dari nilai standar yang ditetapkan dalam syarat mutu arang aktif serbuk teknis (SNI) No. 06-3730-1995 yaitu 15\%. Hal ini disebabkan oleh kandungan air dari karbon aktif telah menguap pada saat proses karbonisasi dan pemanasan dalam oven sebelum dilakukan uji arang aktif.

\section{Kadar Abu}

Kadar abu adalah persentase berat oksida-oksida mineral dalam karbon seperti silikon, sulfur, dan kalsium. Kadar abu yang terukur dalam arang aktif setelah diuji yaitu $2.448 \%$. Nilai kadar abu arang aktif strobilus pinus lebih rendah dibandingkan dengan nilai maksimum yang ditetapkan dalam syarat mutu arang aktif teknis (SNI) No. 06-37301995 yaitu $2.5 \%$.

\section{Kadar Zat Mudah Menguap}

Penetapan kadar zat mudah menguap bertujuan mengetahui jumlah zat atau senyawa yang belum menguap pada proses karbonisasi dan aktivasi. Besarnya kadar zat mudah menguap mengarah kepada kemampuan daya jerap arang aktif. Kadar zat mudah menguap yang tinggi akan mengurangi daya jerap arang aktif tersebut. Kadar zat mudah menguap arang aktif yang dibuat telah memenuhi Standar Nasional Indonesia (SNI) 06-3730-1995 yaitu maksimum $15 \%$. Dalam penelitian ini kadar zat mudah menguap terukur adalah $6.089 \%$.

\section{Kadar Karbon Terikat}

Penentuan kadar karbon terikat bertujuan untuk mengetahui kandungan karbon setelah proses karbonisasi dan aktivasi (Suryani, 2009). Kadar karbon terikat yang terukur pada penelitian ini adalah $91.462 \%$. Nilai kadar karbon terikat dari arang aktif strobilus pinus lebih tinggi dari nilai minimum yang ditetapkan dalam syarat mutu arang aktif teknis (SNI) 06-3730-1995 yaitu $80 \%$.

\section{Kapasitas adsorpsi dan Energi Adsorpsi Arang Aktif Strobilus Pinus}

Kapasitas adsorpsi menggambarkan jumlah maksimum adsorbat yang dapat diadsorpsi oleh adsorben. Saat ini telah ada berbagai model isoterm adsorpsi yang telah dikemukakan oleh beberapa ahli misalnya model isoterm adsorpsi Dubinin-
Raduskevich, isoterm adsorpsi Freundlich, isoterm Langmuir, dan BET (Brunauer, Emmett, dan Teller). Namun untuk adsorpsi senyawa toluena dikuantitaskan dengan parameter Dubinin-Raduskevich.

Tabel 2: Kapasitas Adsorpsi dan Energi Adsorpsi toluena menurut model isoterm adsorpsi Dubinin-Raduskevich

\begin{tabular}{|c|c|c|}
\hline Adsorben & $\begin{array}{c}\text { Kapasitas } \\
\text { Adsorpsi } \\
(\mathbf{W 0}) \\
\left(\mathrm{cm}^{3} / \mathrm{g}\right) \\
\end{array}$ & $\begin{array}{c}\text { Energi } \\
\text { Adsorpsi } \\
(\text { E0) } \\
(\mathrm{kJ} / \mathrm{mol}) \\
\end{array}$ \\
\hline $\begin{array}{l}\text { Arang Strobilus } \\
\text { Pinus }\end{array}$ & 0.0267 & 5.941 \\
\hline $\begin{array}{l}\text { Arang Aktif Strobilus } \\
\text { Pinus }\end{array}$ & 0.1027 & 13.268 \\
\hline $\begin{array}{l}\text { Arang Aktif Serbuk } \\
\text { Gergajian kayu jati* }\end{array}$ & 0.0620 & 8.2923 \\
\hline $\begin{array}{l}\text { Arang Aktif Tongkol } \\
\text { Jagung** }\end{array}$ & 0.0554 & 7.5822 \\
\hline $\begin{array}{l}\text { Arang Aktif } \\
\text { Tempurung } \\
\text { Kelapa*** }\end{array}$ & 0.0686 & 9.2908 \\
\hline * $\quad$ Yadnyana (2011) & & \\
\hline $\begin{array}{ll}* * & \text { Wijaya (2011) } \\
* * * & \text { Poha }(2011)\end{array}$ & & \\
\hline
\end{tabular}

Berdasarkan data pada Tabel 2, terlihat bahwa arang aktif yang terbuat dari strobilus pinus memiliki kapasitas adsorpsi yang cukup besar untuk digunakan sebagai adsorben dibandingkan dengan arang strobilus maupun arang aktif yang lain. Hal ini dikarenakan oleh kapasitas adsorpsi dari suatu arang aktif didasarkan pada besarnya pori dari suatu arang aktif, sedangkan besarnya pori dari suatu arang aktif dipengaruhi oleh jenis pengaktivasi (Pari dan Sailah, 2001). Pada penelitian ini arang aktif strobilus pinus diaktivasi dengan menggunakan $\mathrm{ZnCl}_{2}$ sedangkan untuk arang aktif serbuk gergajian kayu jati, tongkol jagung, dan tempurung kelapa diaktivasi dengan menggunakan $\mathrm{NaCl}$. Menurut Bansal dan Goyal (2005), zat pengaktivasi yang berbeda dan bahan mentah yang berbeda akan menghasilkan arang aktif dengan sifatsifat yang berbeda pula.

Energi adsorpsi adalah kemampuan untuk melepas ikatan antara adsorben (arang aktif) dengan adsorbat (toluena). Hampir sama seperti kapasitas adsorpsi, data pada Tabel 2 menunjukkan bahwa arang yang diaktivasi dengan aktivator $\mathrm{ZnCl}_{2}$ mempunyai 
energi adsorpsi yang lebih besar dibandingkan dengan arang tanpa pengaktivasi maupun arang aktif lain yang menggunakan pengaktivasi $\mathrm{NaCl}$.

Pengotor dapat menyebabkan luas permukaan arang menjadi rendah, menutupi pori dalam struktur arang, dan menghalangi interaksi antara arang aktif dan toluena. Dengan tersingkirnya pengotor dari permukaan arang maka luas permukaan arang menjadi lebih besar, pori-pori dalam struktur arang terbuka, dan interaksi antara arang aktif dan toluena menjadi lebih kuat. Interaksi antara adsorben dengan adsorbat yang kuat akan menghasilkan energi adsorpsi yang lebih besar.

Gambaran energi adsorpsi dari arang aktif strobilus pinus dapat diperoleh dari nilai kadar zat mudah menguap. Semakin tinggi kadar zat mudah menguap maka energi adsorpsi dari karbon aktif semakin rendah. Hal ini karena kadar zat mudah menguap merupakan jumlah dari zat yang belum menguap pada saat proses karbonisasi dan aktivasi, sehingga mempengaruhi energi adsorpsi dari arang aktif (Suryani, 2009).

\section{KESIMPULAN DAN SARAN}

\section{Kesimpulan}

Dari penelitian ini ditemukan bahwa aktivasi arang strobilus pinus dengan $\mathrm{ZnCl}_{2}$ dapat meningkatkan kapasitas adsorpsi dan energi adsorpsi untuk adsorbat toluena. Kapasitas adsorpsi dan energi adsorpsi toluena pada arang aktif strobilus pinus berturut-turut sebesar $0.1027 \mathrm{~cm}^{3} / \mathrm{g}$ dan $13.286 \mathrm{~kJ} / \mathrm{mol}$. Dan untuk arang strobilus tanpa pengaktivasi berturut-turut sebesar $0.0267 \mathrm{~cm}^{3} / \mathrm{g}$ dan $5.941 \mathrm{~kJ} / \mathrm{mol}$.

\section{Saran}

Perlu dilakukan penelitian lebih lanjut mengenai kapasitas dan energi adsorpsi pada arang aktif strobilus pinus dengan senyawa volatil yang berbeda pada kondisi dinamis.

\section{DAFTAR PUSTAKA}

Anonim. 2006. Energy Efficiency and Indoor Air Quality. Energy Services, Western Area Power Administration. Lakewood, USA.

Bansal, C.R., Donnet, J.B., Stoekli, F. 1988. Active Carbon. Marcel Dekker Inc., New York.

Bansal,C.R dan Goyal, M. 2005. Activate Carbon Adsorption. CRC Press. Boca Raton

Ham, M. 2005. Kamus Kimia. Bumi Aksara, Jakarta.

Pari, G. dan I. Sailah, 2001. Pembuatan Arang Aktif Dari Sabut Kelapa Sawit Dengan Bahan Pengaktif $\mathrm{NH}_{4} \mathrm{HCO}_{3}$ dan $\left(\mathrm{NH}_{4}\right)_{2} \mathrm{CO}_{3}$ Dosis Rendah. Buletin Penelitian Hasil Hutan, Bogor.

Poha, L 2011. Isoterm Adsorpsi Toluena Pada Karbon Aktif Tempurung Kelapa [skripsi]. FMIPA UNSRAT, Manado

[SNI] Standar Nasional Indonesia [Dalam Suryani 2009]. 1995. SNI 06-37301995: Arang Aktif Teknis. Jakarta. Dewan Standarisasi Nasional.

Suryani A. M. 2009. Pemanfaatan Tongkol Jagung Untuk Pembuatan Arang Aktif Sebagai Adsorben Pemurnian Minyak Goreng Bekas [skripsi]. FMIPA IPB, Bogor.

Warsito, A. 2007. Analisis Pemajanan Toluena Terhadap Prifil Darah Pada Pekerja Sektor Industri Penyulingan Minyak Bumi [Tesis]. Universitas Diponegoro, Semarang.

Wijaya, I G Putra, 2011. Isoterm Adsorpsi Toluena Pada Karbon Aktif Tongkol Jagung [Skripsi]. FMIPA UNSRAT, Manado.

Yadnyana, I. P. 2011. Adsorpsi Toluena Pada Arang Aktif Serbuk Gergajian Kayu jati (Tectona grandis) [skripsi]. FMIPA UNSRAT, Manado. 